\title{
Assessment of Regional Health Vulnerability to Extreme Heat - China, 2019
}

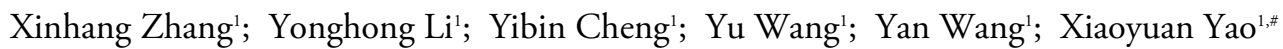

\section{Summary \\ What is already known on this topic?}

The health risk caused by high-temperatures depends on the interaction between high temperature exposure and the sensitivity and adaptability of the affected populations.

\section{What is added by this report?}

A comprehensive assessment model was established by principal component analysis using the data of 19 cities, 15 provincial-level administrative divisions and used to identify regional characteristics and major influencing factors of health vulnerability to extreme heat in China.

What are the implications for public health practice?

The results of the health vulnerability assessment could effectively identify the regions highly vulnerable to extreme heat in China and provide scientific evidence for the development of adaptive measures and resource allocation plans.

With global warming, the impacts of extremely high temperatures on health have been gradually increasing. Due to the differences in population adaptability, socioeconomic development levels, geographical locations, and climatic conditions, health impacts of extremely heat vary across regions. This study intends to construct an evaluation index system, to evaluate the regional health vulnerability to extreme heat, and to identify the major influencing factors of health vulnerability in China. First, a comprehensive assessment model for health vulnerability to extreme heat was established by principal component analysis with the data from 19 representative cities from a national project, which were distributed in different climatic zones (Supplementary Figure S1 available in http://weekly.chinacdc.cn/), and the results were verified by using the proportion of deaths on extreme heat days in the summer. Then, the extreme heathealth vulnerability index of 31 provincial-level administrative divisions (PLADs) in 2019 were calculated using the established comprehensive assessment model. It was found that regions with high vulnerability were mainly located in the western and central China. The major influencing factors of health vulnerability to extreme heat included indicators of healthcare levels, living environment indicators, socioeconomic level indicators, and air quality. This study could effectively identify areas highly vulnerable to extreme heat in China and provide scientific evidence for the development of adaptive measures and resource allocation plans.

Data on air pollutants (e.g., $\mathrm{PM}_{2.5}, \mathrm{NO}_{2}$ ), meteorological factors (e.g., temperature, precipitation), demographics, and socioeconomic conditions were collected from the China Environment Statistical Yearbook, China Meteorological Administration, China Statistical Yearbook, China Urban Statistical Yearbook, China Health Statistics Yearbook, relevant statistical bulletin, and provincial statistical yearbooks. Data in the 19 representative cities, 15 PLADs were collected from 2014 to 2018 and data in the 31 PLADs were collected in 2019. The mortality data from 2014 to 2018 were obtained from China's Cause of Death Reporting System with assistance by local CDCs. In this study, the 95th percentiles of the temperature range were selected as extreme heat temperatures.

The assessment of health vulnerability to extreme heat was conducted in a three-stage analysis. First, the evaluation indicators for health vulnerability to extreme heat were selected in three dimensions including exposure, sensitivity, and adaptability through literature review, correlation analysis, and principal component analysis (PCA). Second, a comprehensive assessment model of health vulnerability to extreme heat was established by a PCA method using data from 19 representative cities in 15 PLADs in which the death data were collected. The value of health vulnerability index of extreme heat was calculated by the following function: vulnerability index $=$ exposure index score + sensitivity index score adaptability index score. The results of the 
vulnerability assessment were verified by correlation analysis between the vulnerability index and the proportion of deaths on extreme heat days. Finally, the extreme heat-health vulnerability indexes of 31 PLADs in 2019 were calculated with the same model in 19 representative cities, 15 PLADs. All analyses were performed using $\mathrm{R}$ statistical software (version 4.0.2; The R Foundation for Statistical Computing, Vienna, Austria).

A total of 20 indicators in 3 dimensions were selected for assessment of health vulnerability to extreme heat, including 6 exposure indicators, 7 sensitivity indicators, and 7 adaptability indicators (Table 1). PCA extracted 4 principal components that had a cumulative variance contribution rate of $77 \%$ (Table 2). The first principal component mainly represented healthcare indicators including the elderly dependency ratio, maternal mortality rate, perinatal mortality rate, morbidity rate of infectious diseases, etc. The second principal component mainly represented living environment factors including the proportion of households with five or more persons, air temperature, etc. The third principal component represented socioeconomic indicators such as the percentage of people living alone, air temperature, per capita gross domestic product (GDP), and electricity demand. The fourth principal component represented air quality conditions that mainly included concentration of $\mathrm{PM}_{2.5}$ and $\mathrm{NO}_{2}$.

The correlation coefficient between the vulnerability index and the proportion of deaths on hot days in summer in 19 representative cities was 0.518

TABLE 1. The selected evaluation indicators of exposure, sensitivity and adaptability for vulnerability assessment.

\begin{tabular}{|c|c|c|}
\hline Dimension & Indicators & Function relationship \\
\hline \multirow{6}{*}{ Exposure } & Annual average temperature $\left({ }^{\circ} \mathrm{C}\right)$ & + \\
\hline & Daily maximum temperature $\geq \mathrm{P}_{95}{ }^{*}$ days & + \\
\hline & Frequency of heat waves ${ }^{*}$ & + \\
\hline & Annual average relative humidity $(\%)$ & + \\
\hline & $\mathrm{PM}_{2.5}\left(\mu \mathrm{g} / \mathrm{m}^{3}\right)$ & + \\
\hline & $\mathrm{NO}_{2}\left(\mathrm{mg} / \mathrm{m}^{3}\right)$ & + \\
\hline \multirow{7}{*}{ Sensitivity } & Elderly dependency ratio $(\%)^{*}$ & + \\
\hline & Poverty population ratio (\%) & + \\
\hline & Living alone $(\%)$ & + \\
\hline & Proportion of households with 5 or more persons ${ }^{*}(\%)$ & + \\
\hline & Maternal mortality rate $(1 / 100,000)$ & + \\
\hline & Perinatal mortality rate* $(\% 0)$ & + \\
\hline & Morbidity rate of infectious diseases ${ }^{*}(1 / 100,000)$ & + \\
\hline \multirow{7}{*}{ Adaptability } & Per capita GDP* ${ }^{*}$ RMB) & - \\
\hline & Per capita medical care ${ }^{\star}(\mathrm{RMB})$ & - \\
\hline & Green coverage rate of built district ${ }^{*}(\%)$ & - \\
\hline & Air conditioning quantity ${ }^{*}$ & - \\
\hline & Electricity demand ${ }^{\star}(100,00 / k W h)$ & - \\
\hline & Daily water consumption ${ }^{*}(\mathrm{~L})$ & - \\
\hline & Volume of precipitation ${ }^{*}$ & - \\
\hline
\end{tabular}

${ }^{*} P_{95}$ is the 95th percentile of the daily maximum temperature; Frequency of heat waves is frequency for 3 consecutive days $\geq P_{95}$ of daily maximum temperature; Elderly dependency ratio is the ratio of the elderly population aged 65 and over to the working-age population aged 15-64; Poverty population ratio is minimum Living Allowances and over to the Total population at year end; Proportion of households with 5 or more persons is the ratio of households with 5 or more persons to the total number of households; Maternal mortality rate is the number of maternal deaths per 100,000 maternal; Perinatal mortality rate is the number of neonatal deaths from 28 weeks of gestation or $\geq 1,000$ grams of birth to 7 days after delivery; Morbidity rate of infectious diseases is the number of cases of Class $A$ and $B$ infectious diseases per 100 thousand population in the reference year; Per capita GDP is per capita gross domestic product, the ratio of the GDP by a region to the permanent population; Per capita medical care expenditure is the expenditure on drugs, supplies and services of medical and health care; Green coverage rate of built district is the percentage of green coverage in urban built-up areas to built-up areas; Air conditioning quantity is per 100 households air conditioning quantity; Electricity demand is annual total electricity consumption in urban households; Life-water quantity is the average Daily water consumption per person; Volume of precipitation is the annual precipitation is the summation of 12 months precipitation of a year. 
TABLE 2. Factor loadings for extreme heat vulnerability for the four retained varimax-rotated based on data from 19 representative cities, 15 PLADs in China from 2014 to 2018.

\begin{tabular}{|c|c|c|c|c|}
\hline Item & $\begin{array}{c}\text { Principal } \\
\text { component } 1\end{array}$ & $\begin{array}{c}\text { Principal } \\
\text { component } 2\end{array}$ & $\begin{array}{c}\text { Principal } \\
\text { component } 3\end{array}$ & $\begin{array}{c}\text { Principal } \\
\text { component } 4\end{array}$ \\
\hline Frequency of heat waves & -0.24 & 0.70 & -0.21 & 0.23 \\
\hline Annual average temperature $\left({ }^{\circ} \mathrm{C}\right)$ & -0.35 & 0.80 & 0.29 & 0.17 \\
\hline Annual average relative humidity (\%) & -0.28 & 0.76 & -0.01 & -0.29 \\
\hline $\mathrm{PM}_{2.5}\left(\mu \mathrm{g} / \mathrm{m}^{3}\right)$ & -0.15 & -0.11 & -0.20 & 0.90 \\
\hline $\mathrm{NO}_{2}\left(\mathrm{mg} / \mathrm{m}^{3}\right)$ & 0.08 & -0.12 & 0.18 & 0.88 \\
\hline Daily maximum temperature $\geq \mathrm{P}_{95}{ }^{*}$ days & 0.17 & 0.49 & 0.04 & -0.02 \\
\hline Elderly dependency ratio (\%) & -0.82 & 0.02 & -0.25 & 0.31 \\
\hline Poverty population ratio (\%) & 0.13 & -0.35 & -0.47 & -0.66 \\
\hline living alone (\%) & -0.07 & 0.08 & 0.85 & -0.21 \\
\hline Proportion of households with 5 or more persons (\%) & 0.23 & 0.81 & -0.09 & 0.09 \\
\hline Maternal mortality rate $(1 / 100,000)$ & 0.89 & -0.17 & -0.28 & 0.07 \\
\hline Perinatal mortality rate $(\%)$ & 0.91 & -0.07 & -0.21 & 0.05 \\
\hline Morbidity rate of infectious diseases $(1 / 100,000)$ & 0.90 & 0.09 & -0.06 & -0.01 \\
\hline Per capita GDP (CNY) & -0.21 & 0.11 & 0.83 & 0.08 \\
\hline Per capita medical care expenditure (CNY) & 0.39 & -0.56 & 0.37 & 0.17 \\
\hline Green coverage rate of built district (\%) & -0.04 & 0.50 & 0.45 & 0.42 \\
\hline Air conditioning quantity & -0.62 & 0.50 & 0.45 & 0.25 \\
\hline Electricity demand $(100,00 / \mathrm{kWh})$ & -0.05 & -0.04 & 0.84 & 0.26 \\
\hline Daily water consumption (L) & 0.06 & 0.77 & 0.36 & -0.10 \\
\hline Volume of precipitation & -0.31 & 0.78 & 0.36 & -0.20 \\
\hline
\end{tabular}

${ }^{*} \mathrm{P}_{95}$ is the 95th percentile of the daily maximum temperature; Bold font is the greater correlation between the evaluation index and the principal component

$(P=0.023)$. We used the same method to evaluate health vulnerability to extreme heat in 31 PLADs (Supplementary Table S1 available in http://weekly. chinacdc.cn/). Results showed that higher vulnerability regions were located in the western and central China (Figure 1). The four highest vulnerability regions were the Tibet (Xizang) Autonomous Region (0.182), Qinghai Province (0.112), Tianjin Municipality (0.076), and Xinjiang Uyghur Autonomous Region $(0.075)$.

\section{DISCUSSION}

In this study, an extreme heat-health vulnerability assessment model that included 20 factors in 3 dimensions was created using data from 19 representative cities, and the health vulnerability to extreme heat in 31 PLADs in China was assessed according to the health vulnerability assessment model. It was found that heat vulnerability varied across regions, with generally higher scores of vulnerability in the western and central China, which could be possibly explained by relative lower adaptability in such areas. Healthcare and living environment factors were important influencing factors of regional vulnerability. Regions with poorer healthcare capacities and higher $\mathrm{PM}_{2.5}$ or $\mathrm{NO}_{2}$ concentration tended to have higher extreme heat vulnerability. The findings could provide scientific evidence for local authorities to improve the local adaptability and decrease the health vulnerability to extreme heat.

The distribution of healthcare resources in China demonstrated some inequalities (1). The medical and healthcare levels in the western region had relatively lower standards (2), where health services were insufficient and access to health information was also limited. In this scenario, people in those regions might be at higher risk when exposed to extreme heat events. For example, western regions of Tibet, Qinghai, and Xinjiang, which had relatively poorer healthcare, had high vulnerability even with their relative mild and temperate climates. Therefore, great efforts should be taken to improve the healthcare conditions in those areas to elevate capability of response to extreme heat 

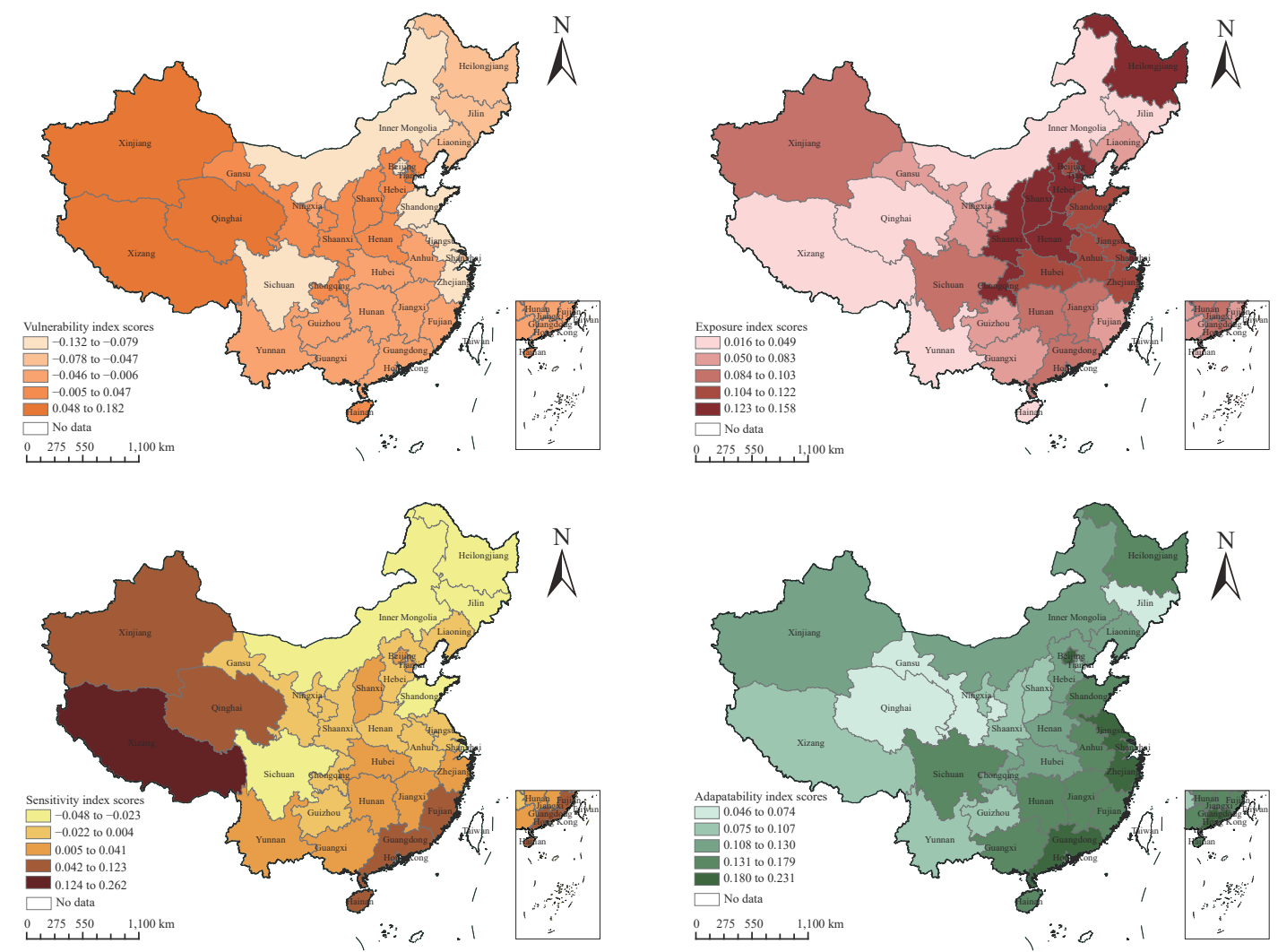

FIGURE 1. National map of extreme heat vulnerability, exposure, sensitivity and adaptability index scores in 31 provinciallevel administrative divisions in China, 2019.

Air quality also presented national spatial variability. The annual $\mathrm{PM}_{2.5}$ and $\mathrm{NO}_{2}$ levels in northern China were higher than those in southern China (3). In recent years, air pollution had caused more than 1 million deaths per year in China (4). Furthermore, a previous study had shown that air pollution could increase the health risks of exposure to heat (5). Therefore, regions with higher concentrations of air pollutants tended to have higher extreme heat vulnerability in the central regions, such as Hebei and Shanxi. With rapid urbanization and development of transport infrastructure, it is also important to improve air quality to reduce extreme high temperature vulnerability.

In addition, it was found that eastern PLADs such as Shandong, Jiangsu, and Zhejiang were at low health vulnerability even with usually higher temperatures in summer. This might be due to the higher levels of the per capita GDP, which is highly correlated to the level of local medical services (Ø). In contrast, due to imbalances, western and central regions had lower economic development ( 7 ), resulting in potentially lower adaptive capacity.

This study was subject to two limitations. First, we excluded some important indicators that were unavailable, such as proportion of population with chronic diseases and high-temperature warnings, which may induce some bias. Second, the lack of provincial health outcome indicators in this study made it impossible to verify the provincial assessment results of health vulnerability to extreme heat. In future studies, we should add a more precise index and optimize the model with more data.

In conclusion, the results of this study showed to some extent that the vulnerability index could reflect comprehensive health effects of extreme heat. Identification of regional health vulnerability to extreme heat can help guide public health authorities to appropriately allocate resources to the more vulnerable regions. A comprehensive adaptation plan should also be developed by local governments to improve local adaptive capacities.

Conflicts of interest: No conflict of interest.

Funding: The Special Foundation of Basic Science and Technology Resources Survey of Ministry of Science and Technology of China (Grant No. 2017FY101201, 2017FY101206).

doi: $10.46234 / \mathrm{ccdcw} 2021.126$ 
\# Corresponding author: Xiaoyuan Yao, yaoxy@chinacdc.cn.

${ }^{1}$ China CDC Key Laboratory of Environment and Population Health, National Institute of Environmental Health, Chinese Center for Disease Control and Prevention, Beijing, China.

Submitted: May 15, 2021; Accepted: June 03, 2021

\section{REFERENCES}

1. Jin J, Wang JX, Ma XY, Wang YD, Li RY. Equality of medical health resource allocation in china based on the gini coefficient method. Iran J Public Health 2015;44(4):445 - 57. https://www.ncbi.nlm.nih.gov/pmc/ articles/PMC4441957/pdf/IJPH-44-445.pdf.

2. Liu YY, Li YH, Li L, Nie XQ, Zhang G, Shi MF, et al. Study on chronic diseases literacy and its influencing factors in China from 2012 to 2017. Chin J Health Educ 2019;35(11):967 - 72. http://dx.doi.org/10.16168/ j.cnki.issn.1002-9982.2019.11.002.
3. Song CB, Wu L, Xie YC, He JJ, Chen X, Wang T, et al. Air pollution in China: status and spatiotemporal variations. Environ Pollut 2017;227: 334 - 47. http://dx.doi.org/10.1016/j.envpol.2017.04.075.

4. Goldberg MS, Burnett RT, Stieb DM, Brophy JM, Daskalopoulou SS, Valois MF, et al. Associations between ambient air pollution and daily mortality among elderly persons in Montreal, Quebec. Sci Total Environ 2013;463-464:931 - 42. http://dx.doi.org/10.1016/j.scitotenv.2013.06. 095.

5. Kinney PL. Interactions of climate change, air pollution, and human health. Curr Environ Health Rep 2018;5(1):179 - 86. http://dx. doi.org/10.1007/s40572-018-0188-x.

6. Hong CP, Zhang Q, Zhang Y, Davis SJ, Tong D, Zheng YX, et al. Impacts of climate change on future air quality and human health in China. Proc Natl Acad Sci USA 2019;116(35):17193 - 200. http://dx doi.org/10.1073/pnas.1812881116.

7. Zhang Y, Wu T, Arkema KK, Han BL, Lu F, Ruckelshaus M, et al. Coastal vulnerability to climate change in China's Bohai Economic Rim. Environ Int 2021;147:106359. http://dx.doi.org/10.1016/j.envint. 2020.106359 


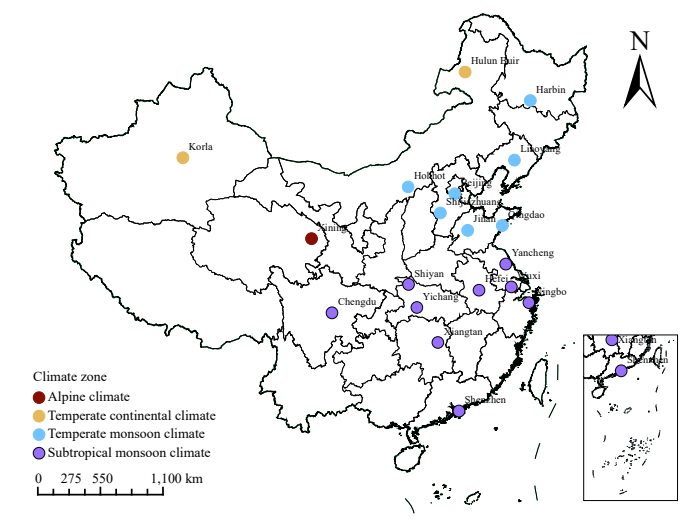

SUPPLEMENTARY FIGURE S1. Location, climate of 19 cities, 15 provincial-level administrative divisionsin China

SUPPLEMENTARY TABLE S1. The analysis results of exposure, sensitivity, adaptability score for the 31 provincial-level administrative divisions in 2019.

\begin{tabular}{|c|c|c|c|c|c|}
\hline Item & Exposure inder & vity inde & ility ind & oility ind & bility ranking \\
\hline Tibet & 0.016 & 0.262 & 0.096 & 0.182 & 1 \\
\hline Qinghai & 0.034 & 0.123 & 0.046 & 0.112 & 2 \\
\hline Tianjin & 0.157 & 0.015 & 0.096 & 0.076 & 3 \\
\hline Xinjiang & 0.091 & 0.096 & 0.112 & 0.075 & 4 \\
\hline Shanxi & 0.133 & 0.021 & 0.107 & 0.047 & 5 \\
\hline Shaanxi & 0.139 & 0.001 & 0.104 & 0.036 & 6 \\
\hline Henan & 0.154 & 0.004 & 0.123 & 0.035 & 7 \\
\hline Chongqing & 0.158 & -0.006 & 0.128 & 0.024 & 8 \\
\hline Gansu & 0.068 & -0.005 & 0.049 & 0.014 & 9 \\
\hline Hebei & 0.148 & -0.017 & 0.127 & 0.004 & 10 \\
\hline Hainan & 0.037 & 0.109 & 0.142 & 0.004 & 11 \\
\hline Hunan & 0.103 & 0.031 & 0.141 & -0.006 & 12 \\
\hline Hubei & 0.109 & 0.006 & 0.130 & -0.015 & 13 \\
\hline Guangdong & 0.089 & 0.121 & 0.230 & -0.020 & 14 \\
\hline Guangxi & 0.075 & 0.041 & 0.143 & -0.028 & 15 \\
\hline Auhui & 0.122 & -0.011 & 0.140 & -0.029 & 16 \\
\hline Ningxia & 0.083 & -0.014 & 0.100 & -0.031 & 17 \\
\hline Fujian & 0.073 & 0.075 & 0.179 & -0.032 & 18 \\
\hline Yunnan & 0.036 & 0.020 & 0.088 & -0.032 & 19 \\
\hline Guizhou & 0.063 & -0.006 & 0.090 & -0.033 & 20 \\
\hline Jiangxi & 0.097 & 0.008 & 0.142 & -0.036 & 21 \\
\hline Liaoning & 0.080 & -0.004 & 0.122 & -0.047 & 22 \\
\hline Heilongjiang & 0.135 & -0.023 & 0.161 & -0.049 & 23 \\
\hline Shanghai & 0.135 & -0.023 & 0.161 & -0.049 & 24 \\
\hline Jilin & 0.049 & -0.026 & 0.074 & -0.051 & 25 \\
\hline Zhejiang & 0.112 & 0.007 & 0.198 & -0.079 & 26 \\
\hline Shandong & 0.111 & -0.030 & 0.163 & -0.082 & 27 \\
\hline Inner Mongolia & 0.048 & -0.023 & 0.114 & -0.090 & 28 \\
\hline Sichuan & 0.097 & -0.048 & 0.146 & -0.097 & 29 \\
\hline Beijing & 0.118 & 0.012 & 0.231 & -0.100 & 30 \\
\hline Jiangsu & 0.112 & -0.013 & 0.231 & -0.132 & 31 \\
\hline
\end{tabular}

